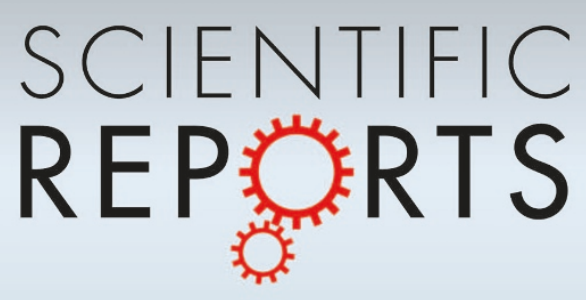

OPEN

SUBJECT AREAS:

DENSITY FUNCTIONAL

THEORY

FUEL CELLS

HETEROGENEOUS CATALYSIS

TWO-DIMENSIONAL MATERIALS

Received

4 July 2013

Accepted

3 January 2014

Published

22 January 2014

Correspondence and requests for materials should be addressed to Y.F.Z. lyfzhu@jlu.edu. cn) or Q.J. (jiangq@jlu. edu.cn)

\section{Layered SiC Sheets: A Potential Catalyst for Oxygen Reduction Reaction}

\author{
P. Zhang ${ }^{1,2}$, B. B. Xiao' , X. L. Hou', ', Y. F. Zhu' \& Q. Jiang'
}

'Key Laboratory of Automobile Materials, Ministry of Education, and Department of Materials Science and Engineering, Jilin University, Changchun 130022, China, ${ }^{2}$ Institute for Advanced Materials, and School of Materials Science and Engineering, Jiangsu University, Zhenjiang 212013, China.

The large-scale practical application of fuel cells cannot come true if the high-priced Pt-based electrocatalysts for oxygen reduction reaction (ORR) cannot be replaced by other efficient, low-cost, and stable electrodes. Here, based on density functional theory (DFT), we exploited the potentials of layered $\mathrm{SiC}$ sheets as a novel catalyst for ORR. From our DFT results, it can be predicted that layered SiC sheets exhibit excellent ORR catalytic activity without $\mathrm{CO}$ poisoning, while the $\mathrm{CO}$ poisoning is the major drawback in conventional Pt-based catalysts. Furthermore, the layered $\mathrm{SiC}$ sheets in alkaline media has better catalytic activity than $\mathrm{Pt}(111)$ surface and have potential as a metal-free catalyst for ORR in fuel cells.

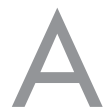

s one of the most promising power sources, fuel cells have received considerable attention due to their high efficiency and low environmental impact. The sluggish kinetics of the oxygen reduction reaction (ORR) at the cathode is one of the key factors limiting the performance of fuel cells, and efficient ORR electrocatalysts are essential for practical applications of the fuel cells. Pt has conventionally been employed as the cathode catalyst due to its high activity for the ORR ${ }^{1,2}$. The high cost, limited supply, and poor durability of Pt catalyst however hinders the large-scale commercialization of fuel cells. Hence, during the last few decades, numerous studies have been devoted to find alternative electrocatalysts for the cathode side of fuel cells, including Pt-based alloys ${ }^{3-6}$, Pt-based core-shell/alloy nanoparticles ${ }^{7-9}$, carbon nanotubes-supported metal particles ${ }^{10,11}$, graphitic carbon nitride/carbon composite ${ }^{12,13} \mathrm{~N} / \mathrm{B} / \mathrm{P} / \mathrm{S}$ doped carbon nanotubes (CNTs) and graphenes ${ }^{14-16}$.

Carbon-based catalysts are expected to be the most promising alternatives to $\mathrm{Pt}$ catalysts because $\mathrm{C}$ is more abundant and durable, as well as less expensive than Pt. The introduction of N (or B, P, S) atoms into $s p^{2}-$ hybridized carbon frameworks of graphenes or CNTs is generally effective in modifying their electrical properties and chemical activities ${ }^{17,18}$. Recent studies have confirmed that N, B, P and S doped carbon materials are hopeful candidates to replace Pt-based catalysts for fuel cells due to their high catalytic activity, long-term stability and excellent CO tolerance ${ }^{14,15,19-23}$. Theoretical studies have confirmed that the improved electrocatalytic activity of these materials can be attributed to the changes of electronic structure by doping N, B, P and S into carbon materials $^{24,25}$. However, the dopant concentration in present carbon-based catalysts is low $(\mathrm{N} \sim 4-6$ at $\%, \mathrm{~B} \sim 0-$ 2.24 at $\%$, and 1-2 at $\%$ of S) ${ }^{19-21}$, which limits the improvement of the catalytic activity of carbon-based catalysts.

$\mathrm{SiC}$ has a unique combination of high saturated carrier mobility, high critical electrical field, and high thermal conductivity. $\mathrm{SiC}$ with the atom ratio of $1: 1$ can provide more active reaction sites than present doped carbon materials to serve as a feasible metal-free ORR electrocatalyst. Herein, we predicted that layered SiC sheets exhibit excellent ORR catalytic activity and high CO tolerance, and may be a very likely candidate for the next generation of low-cost ORR electrocatalysts.

\section{Results}

Firstly, the relative stability between layered and cubic $\mathrm{SiC}$ sheets, which is a function of layer number $N$, is determined by calculating the energy difference $\Delta E=E_{\text {layered }}-E_{\text {cubic }}$, where $E_{\text {layered }}$ and $E_{\text {cubic }}$ are the total energies of layered and cubic $\mathrm{SiC}$ sheets, respectively. The layered $\mathrm{SiC}$ sheets are energetically favorable in comparison to cubic $\mathrm{SiC}$ sheets when $N<4$, while cubic $\mathrm{SiC}$ sheets are advantaged as $N \geq 4$, as shown in Fig. S1 and Table S1 in supporting information. Similar to graphite, layered SiC sheets usually show weak layer-layer interactions. Even further considering the van der Waals bonding, layered SiC sheets are still energetically more favorable than cubic $\mathrm{SiC}$ sheets when $N<4$. This is consistent with the recent experimental results that the thickness of synthesized 2D SiC nanosheets is between 0.5 and $1.5 \mathrm{~nm}^{26}$. 


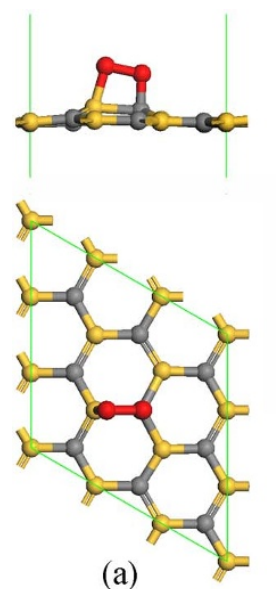

(a)

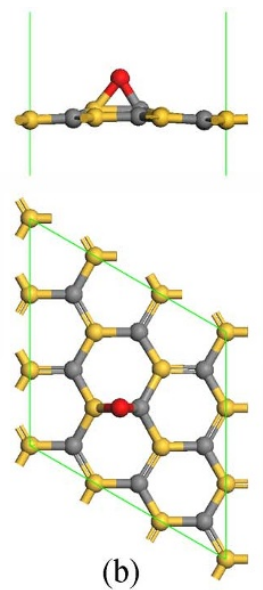

(b)

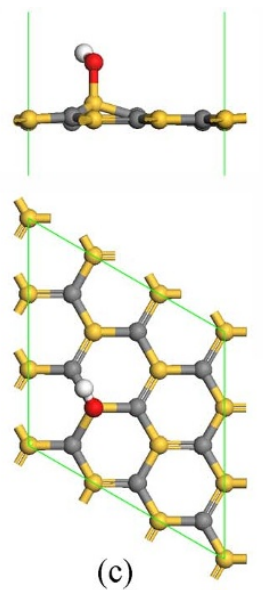

(c)

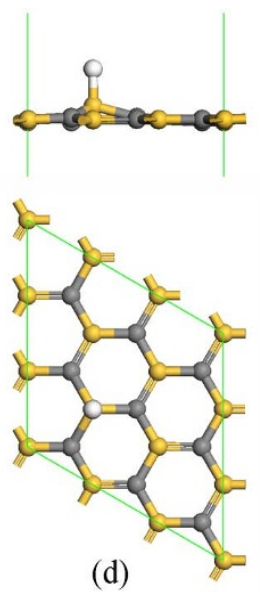

(d)

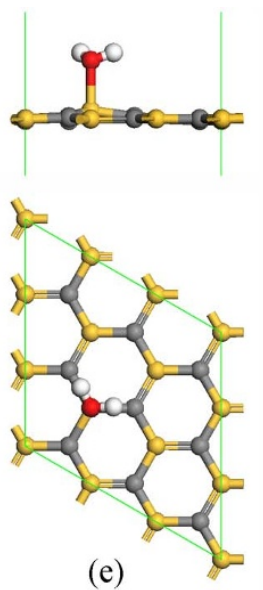

(e)

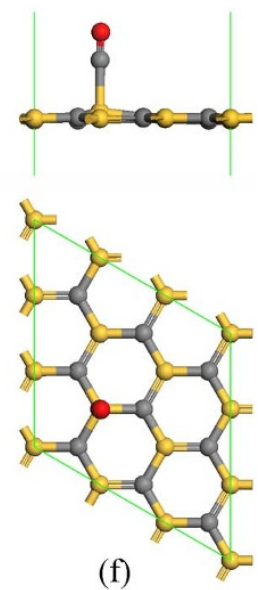

(f)

Figure 1 Optimized adsorption structures for ORR intermediates on a single-layer SiC: (a) $\mathrm{O}_{2}$, (b) $\mathrm{O}$, (c) $\mathrm{OH}$, (d) $\mathrm{H}$, (e) $\mathrm{H}_{2} \mathrm{O}$ and (f) $\mathrm{CO}$. Gray, gold, white and red colors denote $\mathrm{C}, \mathrm{Si}, \mathrm{H}$ and $\mathrm{O}$ atoms.

We then turn to consider the adsorption and reduction of $\mathrm{O}_{2}$ on a single-layer $\mathrm{SiC}$. The adsorption energies of adsorbates on layered $\mathrm{SiC}$ sheets are determined by $E_{\mathrm{ad}}=E_{\mathrm{ads}}+E_{\mathrm{SiC}}-E_{\mathrm{ads} / \mathrm{SiC}}$, where $E_{\mathrm{ads}}$, $E_{\mathrm{SiC}}$ and $E_{\mathrm{ads} / \mathrm{SiC}}$ are the total energies of the isolated adsorbate molecule, the layered $\mathrm{SiC}$ sheets and the adsorption systems, respectively. Positive adsorption energies correspond to exothermic adsorption processes, while negative adsorption energies do endothermic ones. Several possible high-symmetry adsorption sites are considered, including the top, bridge and hollow sites. The most stable adsorption structures and energies of $\mathrm{O}_{2}$ and ORR intermediates are summarized in Fig. 1 and Table 1. The meta-stable adsorption structures and energies are displayed in Fig. S2 of supporting information. It is found that the most energetically favorable site for $\mathrm{O}_{2}$ adsorption on the single-layer $\mathrm{SiC}$ is characterized by $\mathrm{O}_{2}$ nearly parallel to the $\mathrm{SiC}$ bond with adsorption energy of $0.56 \mathrm{eV}$. The $\mathrm{O}-\mathrm{O}$ bond is elongated by $0.29 \AA$ due to the electronic charge transfer from $\mathrm{SiC}$ to the $2 \pi^{*}$ orbital of $\mathrm{O}_{2}$, indicating that $\mathrm{O}_{2}$ can be dissociated easily on $\mathrm{SiC}$. The charge transfer from the single-layer $\mathrm{SiC}$ to $\mathrm{O}_{2}$ molecule is quantified as $0.34 \mathrm{e}$ according to Hirshfeld population charge distribution. Furthermore, the maximum coverage of $\mathrm{O}_{2}$ on $\mathrm{SiC}$ is also explicitly identified. As shown in Table S2 and Fig. S3 of supporting information, only two $\mathrm{O}_{2}$ molecules can be adsorbed on the single-layer $\mathrm{SiC}$ with $2 \times 2$ supercell, corresponding to a coverage $0.5 \mathrm{ML}$ (monolayer) ( $1 \mathrm{ML}$ is defined as one $\mathrm{O}$ atom per surface atom). The adsorption energy of the first $\mathrm{O}_{2}$ molecules on single-layer $\mathrm{SiC}$ is $0.48 \mathrm{eV}$. The second $\mathrm{O}_{2}$ molecule has two distinct adsorption structures with adsorption energies of 0.61 and $0.13 \mathrm{eV}$, respectively. It is found that the energetically more favorable configuration of second $\mathrm{O}_{2}$ forms two chemical bonds with $\mathrm{Si}$ atoms. This special adsorption structure results in the stronger adsorption of the second $\mathrm{O}_{2}$ molecule than the first one. This is because the electronegativity of $\mathrm{Si}(1.90)$ is smaller than that of $\mathrm{C}(2.55)$ while the $\mathrm{Si}-\mathrm{O}$ bond is stronger than the $\mathrm{C}-\mathrm{O}$ bond. Similar results are also found in $4 \times 4$ supercell, where the coverage also reaches $0.5 \mathrm{ML}$. Furthermore, $\mathrm{O}_{2}$ adsorbed as ordered structures in a $4 \times 4$ supercell is considered, as shown in Fig. S3 of supporting information, the corresponding coverage can reach $0.75 \mathrm{ML}$. However, the coverage of $\mathrm{O}_{2}$ on $\mathrm{Pt}(111)$ surface can reach $1 \mathrm{ML}$. All the $\mathrm{O}_{2}$ molecules adsorb on the bridge sites. This is consistent with previous theoretical work about $\mathrm{O}_{2}$ adsorption on $\mathrm{Pt}(111)$ surface ${ }^{27,28}$. Although the coverage of $\mathrm{O}_{2}$ on layered $\mathrm{SiC}$ is smaller than that on $\mathrm{Pt}(111)$ surface, the remaining adsorption sites on single-layer $\mathrm{SiC}$ is favorable for adsorption of other reactants, which may be beneficial for ORR.

The most stable adsorption site for $\mathrm{O}$ atom is the bridge site, which gives rise to a highly stable epoxide-like structure with adsorption energy of $4.18 \mathrm{eV}$. In addition, $\mathrm{H}$ and $\mathrm{OH}$ prefer to adsorbing at atop site of $\mathrm{Si}$ atom other than that of $\mathrm{C}$ atom with the adsorption energies of 1.32 and $2.80 \mathrm{eV}$, respectively, which differs from the case in $\mathrm{N}$ doped carbon materials ${ }^{29}$. Because $\mathrm{H}$ and $\mathrm{OH}$ tend to adsorb at positive charged adsorption sites. Note that $\mathrm{H}_{2} \mathrm{O}$ is stable on atop site of $\mathrm{Si}$ atom of the single-layer $\mathrm{SiC}$. In contrast, $\mathrm{H}_{2} \mathrm{O}$ dissociates to $\mathrm{H}$ and $\mathrm{OH}$ spontaneously on cubic $\mathrm{SiC}$ sheets, which may prevent ORR on cubic $\mathrm{SiC}$ sheets. The reason is that $\mathrm{Si}$ and $\mathrm{C}$ atoms are $s p^{3}$ hybridized in cubic $\mathrm{SiC}$ sheets, while they are $s p^{2}$ in layered ones. The dangling bonds of $\mathrm{Si}$ or $\mathrm{C}$ atoms at the surface of cubic SiC sheets are very active. When $\mathrm{H}$ is introduced to $\mathrm{O}_{2}$, no matter whether the presence of $\mathrm{H}_{2} \mathrm{O}$ molecules around, $\mathrm{O}-\mathrm{O}$ bond dissociates to form $\mathrm{O}$ and $\mathrm{OH}$ spontaneously, as shown in Fig. $\mathrm{S} 4$ of supporting information. $\mathrm{OOH}$ cannot exist as a stable intermediate in the ORR processes. And then, $\mathrm{H}_{2} \mathrm{O}_{2}$ cannot be produced based on $\mathrm{OOH}$. Thus, $\mathrm{OOH}$ and $\mathrm{H}_{2} \mathrm{O}_{2}$ pathways of ORR on the single-layer $\mathrm{SiC}$ are neglected here $\mathrm{e}^{30,31}$.

For $\mathrm{CO}$ adsorption, adsorption energy value changes from $-0.08 \mathrm{eV}$ to $0.07 \mathrm{eV}$ after considering the effect of van der Waals bonding. Since the small adsorption energy value of $\mathrm{CO}$ adsorption, layered $\mathrm{SiC}$ sheets show excellent $\mathrm{CO}$ tolerance. In contrast, the adsorption energy of $\mathrm{CO}$ on $\mathrm{Pt}(111)$ surface $(1.86 \mathrm{eV})$ is twice as large as that of $\mathrm{O}_{2}(0.84 \mathrm{eV})$, as shown in Table $\mathrm{S} 3$ of supporting information. Therefore, $\mathrm{CO}$ blocks the active sites and hinders the ORR on $\mathrm{Pt}(111)$ surface $^{32,33}$. From partial density of states (PDOS) (Fig. S5 of supporting information), it is found that the hybridization between $\mathrm{CO}$ molecule and $\mathrm{Si}$ atom is very small, suggesting that the interaction between $\mathrm{CO}$ and $\mathrm{SiC}$ is little. By contrast, the interaction between $\mathrm{CO}$ and $\mathrm{Pt}(111)$ surface is very strong. All the main orbitals of CO hybridize with Pt states. The renowned mechanism of COmetal interaction, namely, via donation from $\mathrm{CO}-5 \sigma$ to metals and back-donation from metals to $\mathrm{CO}-2 \pi^{*}$ orbital, is applicable for $\mathrm{CO}$ adsorbed on $\operatorname{Pt}(111)^{34,35}$. This is confirmed by the fact of electron depletion at CO- $5 \sigma$ and partially occupied $\mathrm{CO}-2 \pi^{*}$, which is empty

Table 1 | Adsorption energy $\left(E_{\mathrm{ad}}\right)$ values of ORR intermediates on layered $\mathrm{SiC}$ sheets. All results are in unit of $\mathrm{eV}$. SiC-N denotes $\mathrm{N}$ layered $\mathrm{SiC}$ sheet

\begin{tabular}{lcccccc} 
& $\mathrm{O}_{2}$ & $\mathrm{O}$ & $\mathrm{OH}$ & $\mathrm{H}$ & $\mathrm{H}_{2} \mathrm{O}$ & $\mathrm{CO}$ \\
\hline $\mathrm{SiC}-1$ & 0.53 & 4.12 & 2.80 & 1.32 & 0.17 & -0.08 \\
& $(0.66)^{\mathrm{a}}$ & $(4.20)^{\mathrm{a}}$ & $(2.92)^{\mathrm{a}}$ & $(1.38)^{\mathrm{a}}$ & $(0.32)^{\mathrm{a}}$ & $(0.07)^{\mathrm{a}}$ \\
$\mathrm{SiC}-2$ & 0.46 & 4.09 & 2.93 & 1.41 & 0.18 & -0.09 \\
$\mathrm{SiC}-3 / \mathrm{ABA}$ & 0.50 & 4.11 & 2.87 & 1.35 & 0.15 & -0.07 \\
$\mathrm{SiC}-3 / \mathrm{ABC}$ & 0.56 & 4.14 & 2.86 & 1.35 & 0.10 & -0.09 \\
\hline
\end{tabular}

The energies in parenthesis are performed under the consideration of van der Waals bonding. 
(a)

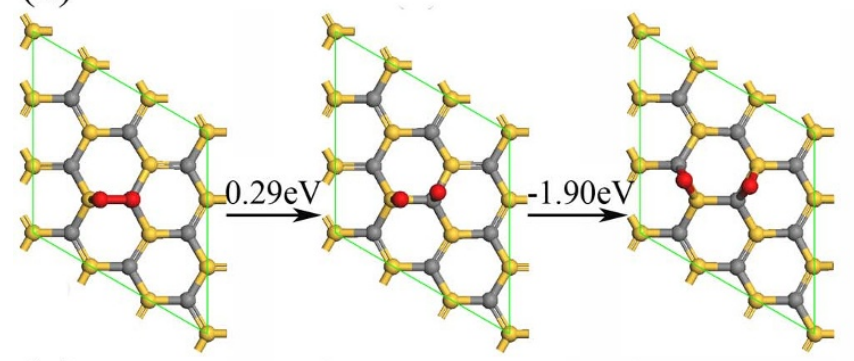

(c)

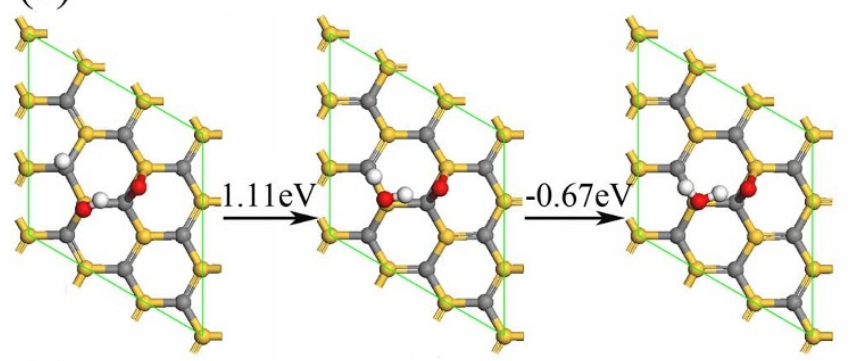

(e)

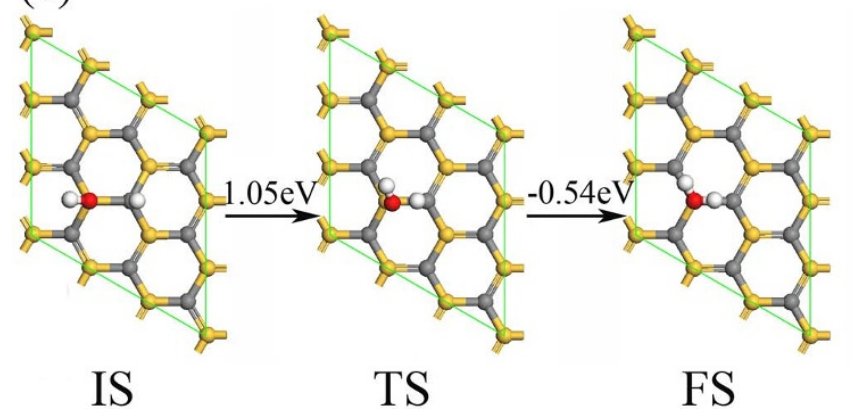

(b)

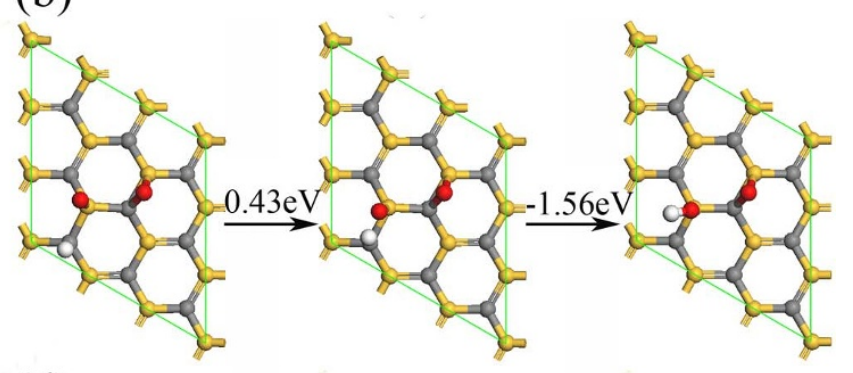

(d)

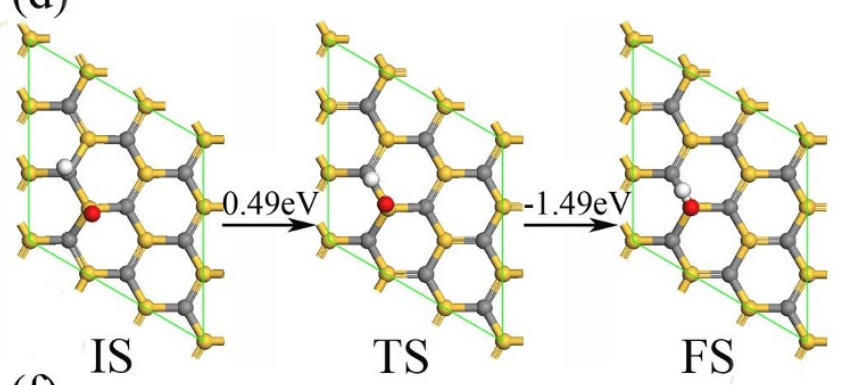

(f)

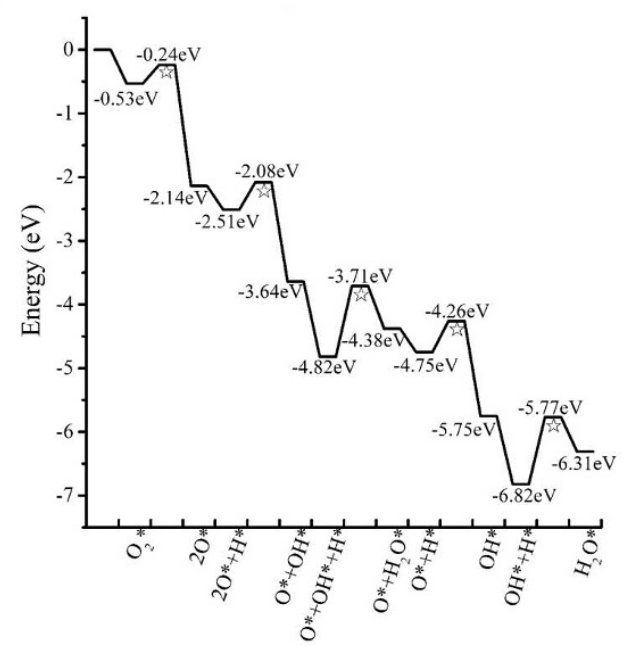

Figure $2 \mid$ Minimum energy pathways for ORR elemental steps in acidic media on a single-layer $\mathrm{SiC}:(\mathrm{a}) \mathrm{O}_{2} \rightarrow 2 \mathrm{O},(\mathrm{b}) 2 \mathrm{O}+\mathrm{H} \rightarrow \mathrm{O}+\mathrm{OH},(\mathrm{c}) \mathrm{O}+\mathrm{OH}$ $+\mathrm{H} \rightarrow \mathrm{O}+\mathrm{H}_{2} \mathrm{O},(\mathrm{d}) \mathrm{O}+\mathrm{H} \rightarrow \mathrm{OH},(\mathrm{e}) \mathrm{OH}+\mathrm{H} \rightarrow \mathrm{H}_{2} \mathrm{O}$, and (f) schematic energy profile. IS, TS and FS are initial, transition and final states, respectively. Gray, gold, white and red colors denote $\mathrm{C}, \mathrm{Si}, \mathrm{H}$ and $\mathrm{O}$ atoms.

above the Fermi level in gas CO. Consequently, $\mathrm{CO}$ will poison the $\operatorname{Pt}(111)$ surface.

It is known that ORR mechanisms at cathodes in acidic and alkaline solutions are different. In an acidic solution, the electrode reaction can be written as $\mathrm{O}_{2}+4 \mathrm{H}^{+}+4 \mathrm{e}^{-} \rightarrow 2 \mathrm{O}+4 \mathrm{H}^{+}+4 \mathrm{e}^{-} \rightarrow \mathrm{O}+$ $\mathrm{OH}+3 \mathrm{H}^{+}+3 \mathrm{e}^{-} \rightarrow \mathrm{O}+\mathrm{H}_{2} \mathrm{O}+2 \mathrm{H}^{+}+2 \mathrm{e}^{-} \rightarrow \mathrm{OH}+\mathrm{H}_{2} \mathrm{O}+\mathrm{H}^{+}+$ $\mathrm{e}^{-} \rightarrow 2 \mathrm{H}_{2} \mathrm{O}$, while in an alkaline solution that can be expressed as $\mathrm{O}_{2}$ $+2 \mathrm{H}_{2} \mathrm{O}+4 \mathrm{e}^{-} \rightarrow \mathrm{O}+2 \mathrm{OH}^{-}+\mathrm{H}_{2} \mathrm{O}+2 \mathrm{e}^{-} \rightarrow 4 \mathrm{OH}^{-}$. Both reaction pathways are considered here. In general, ORR can proceed in Langmuir-Hinshelwood (LH) or Eley-Rideal (ER) mechanisms. LH mechanism involves all the reacting intermediates on the surface, whereas ER mechanism involves species from the electrolyte reacting with a surface intermediate. Both mechanisms are also taken into account one by one.

The ORR following the LH mechanism is discussed firstly. The ORR mechanism on the single-layer $\mathrm{SiC}$ in $\mathrm{LH}$ mechanism under acidic media can be divided into five elemental steps: $\mathrm{O}_{2}$ dissociation, two $\mathrm{O}$ atom hydrogenation steps and two $\mathrm{OH}$ hydrogenation steps, as shown in Fig. 2. Some possible ORR pathways with higher barrier energies are shown in Fig. S6 of supporting information. The activation energies for the five elemental steps are $0.29 \mathrm{eV}$ for $\mathrm{O}_{2}$ dissociation, 0.43 and $0.49 \mathrm{eV}$ for first and second $\mathrm{OH}$ formation, 1.11 and $1.05 \mathrm{eV}$ for first and second $\mathrm{H}_{2} \mathrm{O}$ formation, respectively. The corresponding reaction energies are $-1.61,-1.13,-1.00,0.44$ and $0.51 \mathrm{eV} . \mathrm{H}_{2} \mathrm{O}$ formation is the rate-determining step (RDS) in the $\mathrm{O}_{2}$ dissociation mechanism of ORR in the above process. The Si$\mathrm{H}$ bond broken from the initial state to the transition state contributes to the most part of the activation energy of $\mathrm{H}_{2} \mathrm{O}$ formation. As the number of $\mathrm{H}$ atoms introduced to the $\mathrm{O}$ atom increases, the activation energy increases from $0.49 \mathrm{eV}$ to $1.05 \mathrm{eV}$ and the reaction energy increases from $-1 \mathrm{eV}$ to $0.51 \mathrm{eV}$, corresponding to the Brønsted-Evans-Polanyi relation between activation energy and reaction energy in the heterogeneous catalysis ${ }^{36-38}$. Activation energy is a almost linear function of reaction energy, and reactions belong to the same class even follow the same relation ${ }^{36-38}$. The decrease of the activity of $\mathrm{O}$ atom is due to the increase of the number of introduced $\mathrm{H}$ atoms.

ORR on the single-layer $\mathrm{SiC}$ in $\mathrm{LH}$ mechanism under an alkaline environment can be divided into the two elemental steps: $\mathrm{O}_{2}+\mathrm{H}_{2} \mathrm{O}$ $\rightarrow \mathrm{O}+2 \mathrm{OH}$ and $\mathrm{O}+\mathrm{H}_{2} \mathrm{O} \rightarrow 2 \mathrm{OH}$, as shown in Fig. 3. Differing from that in acidic environment, both steps are easy to cross with small activation energies $(0.11$ and $0.23 \mathrm{eV})$ and exothermic reaction 
(a)

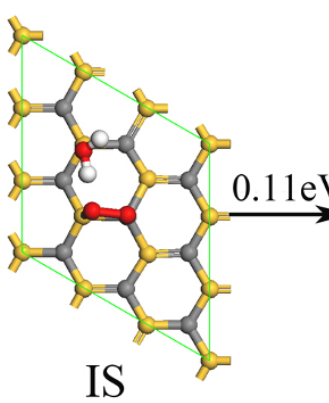

IS

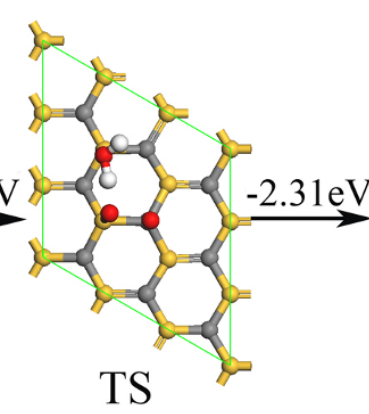

TS

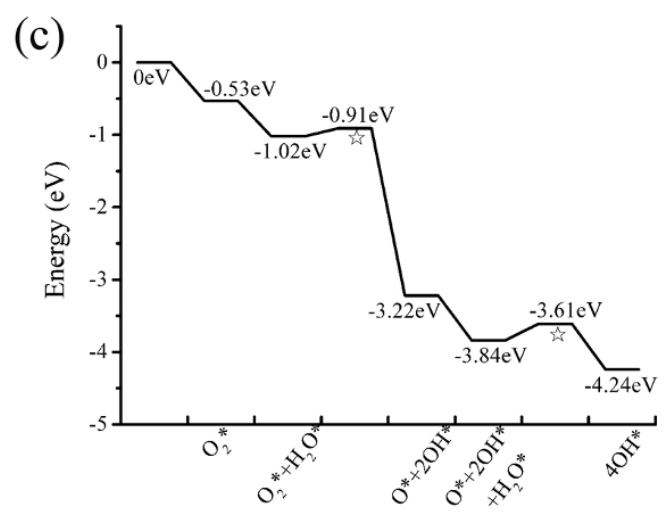

(b)

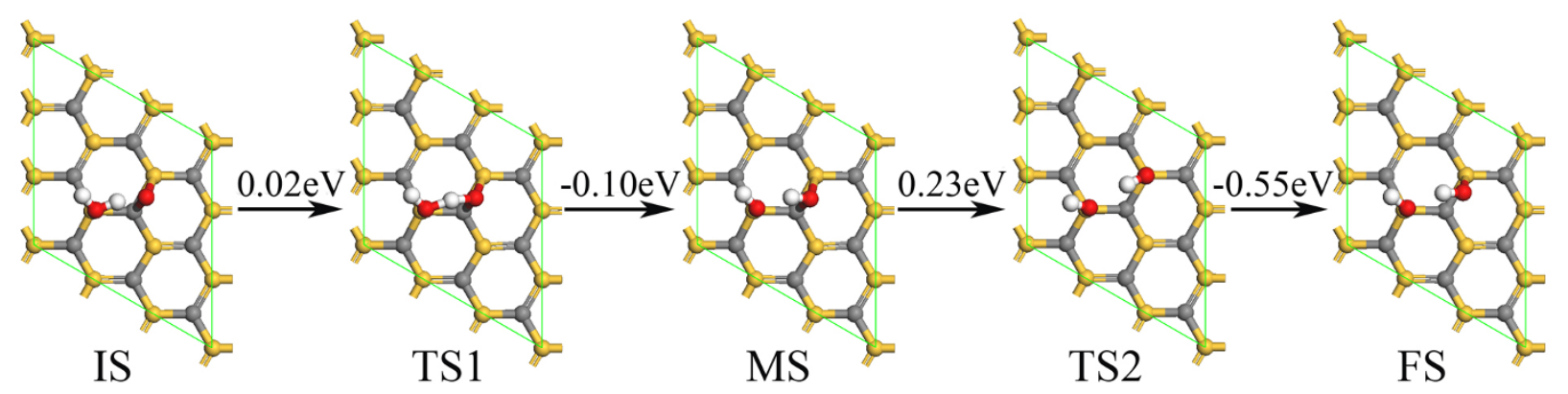

Figure 3 Minimum energy pathways for ORR elemental steps in alkaline media on a single-layer SiC: (a) $\mathrm{O}_{2}+\mathrm{H}_{2} \mathrm{O} \rightarrow \mathrm{O}+2 \mathrm{OH},(\mathrm{b}) \mathrm{O}+\mathrm{H}_{2} \mathrm{O} \rightarrow$ $2 \mathrm{OH}$, and (c) schematic energy profile. IS, TS, MS and FS are initial, transition, metastable and final states, respectively. is denotes the TS in each step. Gray, gold, white and red colors denote $\mathrm{C}, \mathrm{Si}, \mathrm{H}$ and $\mathrm{O}$ atoms.

energies $(-2.20$ and $-0.40 \mathrm{eV})$. These can be deduced from the special geometrical parameters along reaction paths. $\mathrm{O}$ and $\mathrm{H}$ atoms only need a little movement from the initial state to the transition state, which costs little energy. Furthermore, the hydrogen bond between $\mathrm{O}$ atom and $\mathrm{H}$ atom in $\mathrm{H}_{2} \mathrm{O}$ molecule also reduce the energy barrier for $\mathrm{H}$ atom transfer. The activation energies for isolated $\mathrm{H}_{2} \mathrm{O}$ and $\mathrm{O}_{2}$ dissociations are 0.56 and $0.29 \mathrm{eV}$, both of them are surmountable at room temperature. This is consistent with the small activation energies for ORR elemental steps in alkaline media. Thus, we predict that ORR in LH mechanism on the singlelayer $\mathrm{SiC}$ in the alkaline media is more favorable than that in the acidic media.

As $N$ increases from 1 to 3 , adsorption energies for ORR intermediates, activation and reaction energies for ORR elemental steps in LH mechanism on layered $\mathrm{SiC}$ sheets are almost unchanged as shown in Tables 1 and 2. Thus, layered SiC sheets with different $N$ values should show similar ORR catalytic activities.

For a comparison purpose, ORR elemental steps in LH mechanism on $\mathrm{Pt}(111)$ surface are also calculated, as depicted in Fig. S7 and Tables S4 of supporting information. The five barriers in $\mathrm{O}_{2}$ dissociation mechanism are calculated to be $0.85 \mathrm{eV}$ for $\mathrm{O}_{2}$ dissociation, 1.00 and $1.22 \mathrm{eV}$ for two $\mathrm{OH}$ formation steps, and $0.38 \mathrm{eV}$ for
$\mathrm{H}_{2} \mathrm{O}$ formation. For the $\mathrm{OOH}$ association mechanism, it is found that the barriers are $0.61 \mathrm{eV}$ for $\mathrm{OOH}$ formation, $0.03 \mathrm{eV}$ for $\mathrm{OOH}$ dissociation, $1.22 \mathrm{eV}$ for $\mathrm{OH}$ formation, and $0.38 \mathrm{eV}$ for $\mathrm{H}_{2} \mathrm{O}$ formation. $\mathrm{OH}$ formation is RDS for both the $\mathrm{O}_{2}$ dissociation and $\mathrm{OOH}$ association mechanisms. This is consistent with the recent literature $^{30}$. The RDS of ORR on $\mathrm{Pt}(111)$ surface in acidic media is the O atom hydrogenation to $\mathrm{OH}$ with activation energy of $1.22 \mathrm{eV}$, which is similar to that of ORR on layered $\mathrm{SiC}$ sheets, suggesting that layered $\mathrm{SiC}$ sheets and $\mathrm{Pt}(111)$ surface may exhibit similar activities for ORR in LH mechanism under an acidic environment. In the alkaline media, however, the activation energies for the two elemental ORR steps in LH mechanism on $\mathrm{Pt}(111)$ surface are 0.43 and $0.55 \mathrm{eV}$, respectively, both of them are larger than that on layered $\mathrm{SiC}$ sheets since the bond length of Pt-Pt $(2.77 \AA)$ is longer than that of Si-C (1.79 $\AA$ ). The energy cost for the longer distance diffusion of $\mathrm{H}$ atom on $\mathrm{Pt}(111)$ surface is larger than that on layered $\mathrm{SiC}$ sheets. In addition, the elemental step of $\mathrm{O}+\mathrm{H}_{2} \mathrm{O} \rightarrow 2 \mathrm{OH}$, which is the RDS of ORR in LH mechanism on $\mathrm{Pt}(111)$ surface in alkaline media, is endothermic by $0.51 \mathrm{eV}$, while that on layered $\mathrm{SiC}$ sheets is exothermic with reaction energy of nearly $-0.40 \mathrm{eV}$, suggesting that ORR in $\mathrm{LH}$ mechanism on layered $\mathrm{SiC}$ sheets is more advantaged than that on $\mathrm{Pt}(111)$ surface in alkaline environment.

Table 2 | The activation energies $\left(E_{\mathrm{a}}\right)$ and reaction energies $\left(E_{\mathrm{r}}\right)$ for elemental steps involved in ORR in LH mechanism on layered SiC sheets. All results are in unit of $\mathrm{eV}$. SiC-N denotes $\mathrm{N}$ layered $\mathrm{SiC}$ sheet

\begin{tabular}{|c|c|c|c|c|c|c|c|c|}
\hline Reaction steps & \multicolumn{2}{|c|}{$\mathrm{SiC}-1$} & \multicolumn{2}{|c|}{$\mathrm{SiC}-2$} & \multicolumn{2}{|c|}{$\mathrm{SiC}-3 / \mathrm{ABA}$} & \multicolumn{2}{|c|}{$\mathrm{SiC}-3 / \mathrm{ABC}$} \\
\hline $\begin{array}{l}\mathrm{O}_{2} \rightarrow 2 \mathrm{O} \\
2 \mathrm{O}+\mathrm{H} \rightarrow \mathrm{OH}+\mathrm{O} \\
\mathrm{O}+\mathrm{OH}+\mathrm{H} \rightarrow \mathrm{H}_{2} \mathrm{O}+\mathrm{O} \\
\mathrm{O}+\mathrm{H} \rightarrow \mathrm{OH} \\
\mathrm{OH}+\mathrm{H} \rightarrow \mathrm{H}_{2} \mathrm{O} \\
\mathrm{O}_{2}+\mathrm{H}_{2} \mathrm{O} \rightarrow \mathrm{O}+2 \mathrm{OH} \\
\mathrm{O}+\mathrm{H}_{2} \mathrm{O} \rightarrow 2 \mathrm{OH}\end{array}$ & $\begin{array}{l}0.29 \\
0.43 \\
1.11 \\
0.49 \\
1.05 \\
0.11 \\
0.23\end{array}$ & $\begin{array}{r}-1.61 \\
-1.13 \\
0.44 \\
-1.00 \\
0.51 \\
-2.20 \\
-0.40\end{array}$ & $\begin{array}{l}0.27 \\
0.38 \\
1.09 \\
0.45 \\
1.02 \\
0.09 \\
0.20\end{array}$ & $\begin{array}{r}-1.60 \\
-1.21 \\
0.39 \\
-1.12 \\
0.46 \\
-3.25 \\
-0.53\end{array}$ & $\begin{array}{l}0.29 \\
0.40 \\
1.08 \\
0.45 \\
1.03 \\
0.09 \\
0.23\end{array}$ & $\begin{array}{r}-1.59 \\
-1.18 \\
0.41 \\
-1.06 \\
0.50 \\
-2.29 \\
-0.46\end{array}$ & $\begin{array}{l}0.29 \\
0.41 \\
1.09 \\
0.47 \\
1.04 \\
0.08 \\
0.21\end{array}$ & $\begin{array}{r}-1.59 \\
-1.13 \\
0.45 \\
-0.99 \\
0.54 \\
-2.32 \\
-0.48\end{array}$ \\
\hline
\end{tabular}




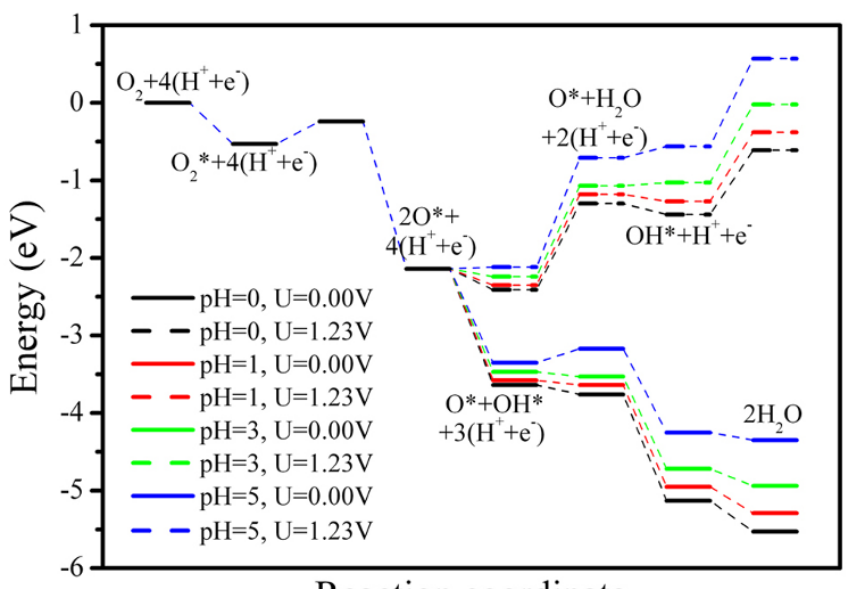

Reaction coordinate

(a)

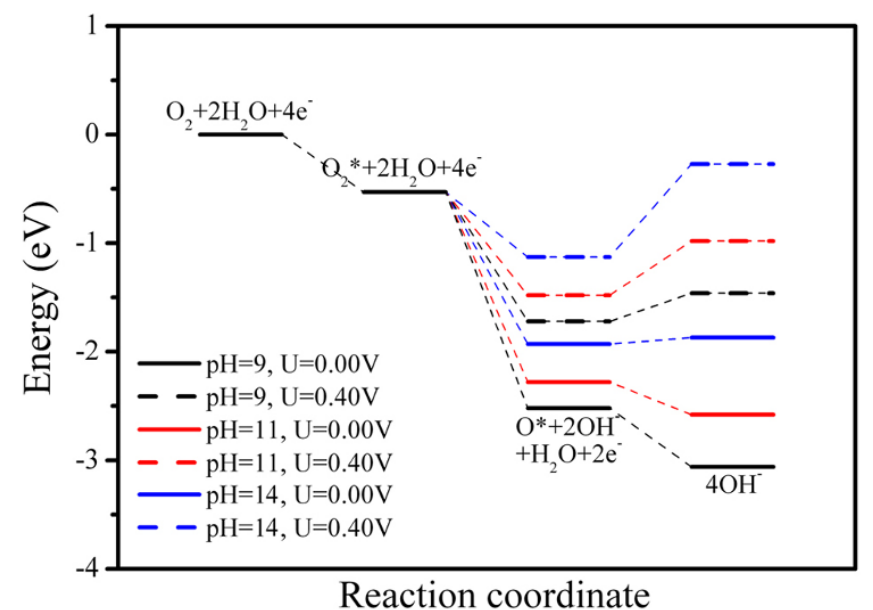

(b)

Figure 4 Schematic energy profile (relative to molecular $\mathrm{O}_{2}+2 \mathrm{H}_{2}$ in acidic media and molecule $\mathrm{O}_{2}+2 \mathrm{H}_{2} \mathrm{O}$ in alkaline media) for the ORR pathway on a single-layer SiC: (a) in acidic media, (b) in alkaline media.

Although energy diagram of ORR in ER mechanism is quite different from that in LH mechanism, both of which show similar results somehow. As shown in Fig. 4(a), ORR in ER mechanism exhibits exothermic reactivity at electrode potential $U=0 \mathrm{~V}$ under an acidic medium. As the $\mathrm{pH}$ value increases, the energy of each net coupled proton and electron transfer (CPET) step is shifted due to the effect of concentration on the free energy of $\mathrm{H}^{+}$. At $\mathrm{pH}=1$, the reaction energies of five elemental steps calculated are $-1.61 \mathrm{eV}$ for $\mathrm{O}_{2}$ dissociation, -1.44 and $-1.32 \mathrm{eV}$ for first and second $\mathrm{OH}$ formation, -0.06 and $-0.34 \mathrm{eV}$ for first and second $\mathrm{H}_{2} \mathrm{O}$ formation, respectively. When $\mathrm{pH} \geq 4$, the reaction energy of first $\mathrm{H}_{2} \mathrm{O}$ formation changes from exothermic to endothermic, while other steps remain exothermic. As $U$ increases from $0 \mathrm{~V}$ to the ideal electrode potential of $1.23 \mathrm{~V}$, energy levels are shifted for each net CPET step $^{31,39}$. The reaction energies of the reactions in the LH mechanism and $\mathrm{O}_{2}$ dissociation in the $\mathrm{ER}$ mechanism remain unchanged. This is because no CPET step involves in these steps and the electrode potential only affects the energy levels of the electrons in the CPET steps $^{31,39}$. At $U=1.23 \mathrm{~V}, \mathrm{OH}$ formation in ER mechanism is still exothermic, while two $\mathrm{H}_{2} \mathrm{O}$ formation steps change to 1.17 and $0.89 \mathrm{eV}$ endothermically at $\mathrm{pH}=1$, respectively. Consistent with ORR in LH mechanism, $\mathrm{H}_{2} \mathrm{O}$ formation is also the RDS of ORR on single $\mathrm{SiC}$ layer in ER mechanism at $U=1.23 \mathrm{~V}$. The high concentration of $\mathrm{H}_{2} \mathrm{O}$ in electrolyte can improve the rate constant for the backward reaction and may have a negative effect on the entire process. Just as any coin has two sides, the issue being discussed here is no exception. $\mathrm{H}_{2} \mathrm{O}$ solution also has some positive effects on the ORR. As shown in Table $\mathrm{S} 5$ of supporting information, the adsorption of $\mathrm{O}_{2}$ is enhanced in $\mathrm{H}_{2} \mathrm{O}$ solution, resulting in the increase of reactant concentration on catalyst surface and forward reaction rate.

A substantially different picture is obtained for ORR in ER mechanism under alkaline environment. Similar with that under acidic media, $\mathrm{pH}$ imports similar effect and shifts up the energy level of every CPET step. As shown in Fig. 4(b), at $U=0 \mathrm{~V}$, adsorbed $\mathrm{O}_{2}$ molecule reaction with $\mathrm{H}_{2} \mathrm{O}$ is exothermic with reaction energy of $-1.40 \mathrm{eV}$, while $\mathrm{O}$ atom reaction with $\mathrm{H}_{2} \mathrm{O}$ is endothermic with reaction energy of $0.06 \mathrm{eV}$ at $\mathrm{pH}=14$. When an ideal electrode potential of $0.40 \mathrm{~V}$ is applied, the energy levels of every CPET step are shifted up by $0.80 \mathrm{eV}$ for every double CPET step. The reaction energies of $\mathrm{O}_{2}$ molecule reaction with $\mathrm{H}_{2} \mathrm{O}$ and $\mathrm{O}$ atom reaction with $\mathrm{H}_{2} \mathrm{O}$ vary to -0.60 and $0.86 \mathrm{eV}$ at $\mathrm{pH}=14 . \mathrm{O}_{2}$ molecule reaction with $\mathrm{H}_{2} \mathrm{O}$ is the $\mathrm{RDS}$ of ORR in ER mechanism under alkaline environment and the energy barrier increases as electrode potential increases.
ORR in ER mechanism on Pt(111) surface is also calculated. As shown in Fig. S8(a) of supporting information, all elemental steps involved in ORR via ER mechanism on $\mathrm{Pt}(111)$ are exothermic at $\mathrm{pH}$ $=1$ and $U=0 \mathrm{~V}$, while $\mathrm{OH}, \mathrm{H}_{2} \mathrm{O}$ and $\mathrm{OOH}$ formations are 0.69 , 0.53 and $0.63 \mathrm{eV}$ endothermic at $U=1.23 \mathrm{~V}$, which are smaller than the barrier of the RDS step $\left(\mathrm{H}_{2} \mathrm{O}\right.$ formation) on single-layer SiC. These results are consistent with that obtained by Nørskov et al, where the reaction energy of $\mathrm{OH}$ and $\mathrm{H}_{2} \mathrm{O}$ formations change form exothermic to endothermic at $U=1.23 \mathrm{~V}$ and the $\mathrm{OOH}$ associative mechanism has the lowest barrier and dominates at low oxygen coverges $^{40,41}$. Fig. S8(b) of supporting information also shows the energy diagram of ORR in ER mechanism on $\mathrm{Pt}(111)$ under alkaline environment. At $U=0 \mathrm{~V}$ and $\mathrm{pH}=1$, the reaction energies of $\mathrm{O}_{2}$ molecule reaction with $\mathrm{H}_{2} \mathrm{O}$ and $\mathrm{O}$ atom reaction with $\mathrm{H}_{2} \mathrm{O}$ on $\operatorname{Pt}(111)$ surface are -1.42 and $0.38 \mathrm{eV}$, respectively. At $U=$ $0.40 \mathrm{~V}$ and $\mathrm{pH}=1$, the reaction energies of these two elemental steps vary to -0.62 and $1.18 \mathrm{eV}$, respectively. $\mathrm{O}_{2}$ molecule reaction with $\mathrm{O}$ atom is the RDS, and the barrier are larger than that on single $\mathrm{SiC}$ layer, suggesting that layered $\mathrm{SiC}$ sheets exhibit better catalytic activity than $\operatorname{Pt}(111)$ surface in ER mechanism under alkaline environment.

Based on Eyring's canonical transition state theory, our calculations can be incorporated into a reduced kinetic model that should report qualitative features of the reaction mechanisms at different applied potentials ${ }^{39,42,43}$. As displayed in Fig. 5(a), the RDS of ORR in ER mechanism is $\mathrm{O}_{2}$ dissociation at low potential region, while it changes to $\mathrm{H}_{2} \mathrm{O}$ formation when $U>0.63 \mathrm{~V}$ at $\mathrm{pH}=1$. As shown in Fig. 5(b), $\mathrm{O}_{2}$ reaction with $\mathrm{H}_{2} \mathrm{O}$ is the $\mathrm{RDS}$ of ORR in ER mechanism under alkaline environment and the reaction rate decreases as electrode potential increases. Comparing Fig. 5 with Fig. S9 of supporting information, we can predict that the catalytic activity of layered $\mathrm{SiC}$ sheets is better than that of $\operatorname{Pt}(111)$ surface in alkaline media. Furthermore, due to the higher doped ratio, $\mathrm{SiC}$ can provide more ORR active sites than present doped carbon materials and may act as a feasible low-cost metal-free ORR electrocatalyst.

\section{Discussion}

Since $\mathrm{O}_{2}$ adsorption and dissociation are the key points for ORR on layered $\mathrm{SiC}$ sheets, the origin of the interaction between $\mathrm{O}_{2}$ and the single-layer $\mathrm{SiC}$ is investigated by considering their electronic structure changes. Fig. S9 of supporting information illustrates the spinpolarized partial density of states (PDOS) of O-O bond on the singlelayer $\mathrm{SiC}$ and $\mathrm{Pt}(111)$ surface. Generally, the $5 \sigma, 1 \pi$ and $2 \pi^{*}$ orbitals of $\mathrm{O}_{2}$ dominate the adsorption and all of them are broadened due to 


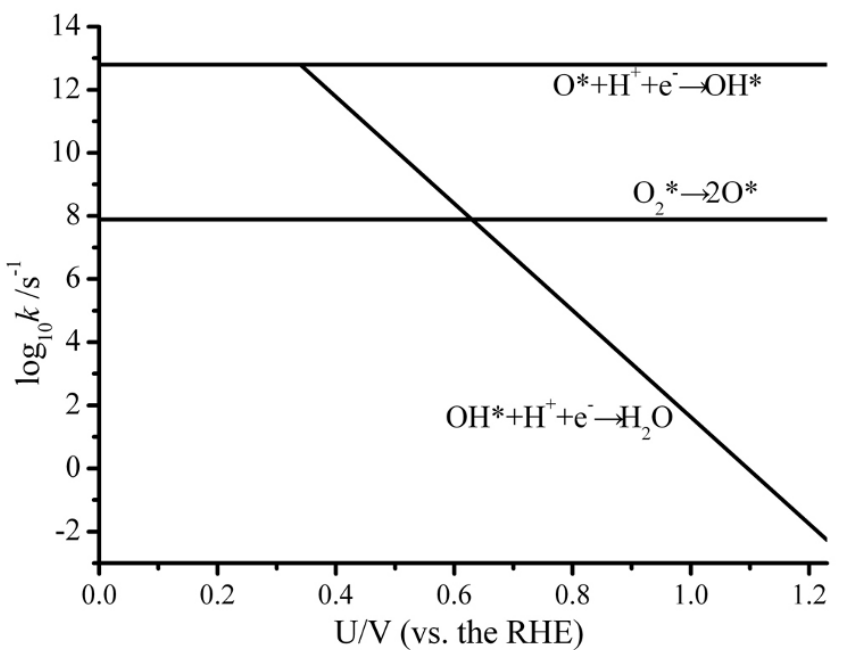

(a)

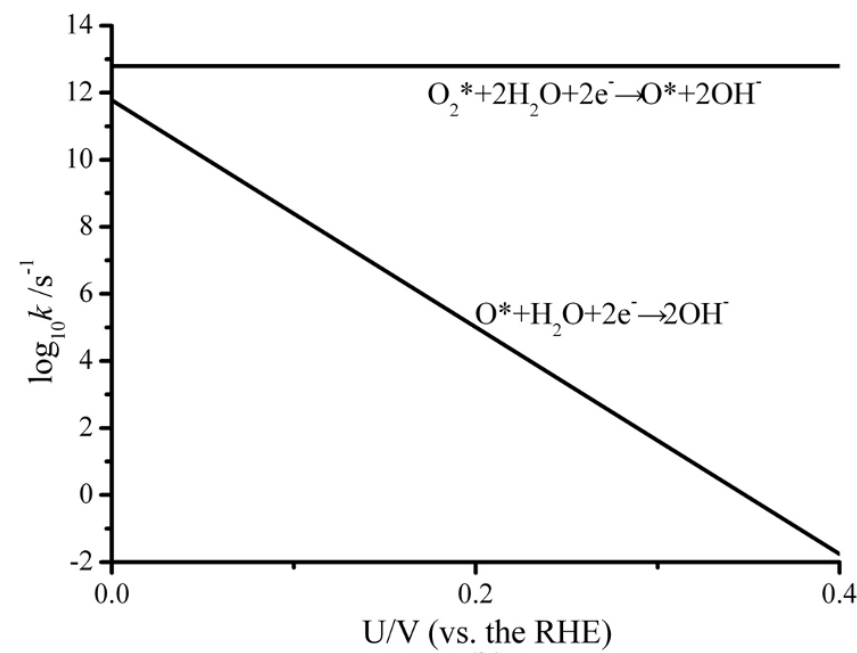

(b)

Figure $5 \mid$ Potential-dependent rate constants for ORR on a single-layer SiC: (a) in acidic media with $\mathrm{pH}=1$, (b) in alkaline media with $\mathrm{pH}=14$.

the interaction with the single-layer $\mathrm{SiC}$ and $\mathrm{Pt}(111)$ surface. The antibonding $4 \sigma^{*}$ state is not involved in the adsorption because its position is far below the Fermi level. The antibonding $2 \pi^{*}$ orbital of gas $\mathrm{O}_{2}$ is partially filled. After adsorption on the single-layer $\mathrm{SiC}$ and $\mathrm{Pt}(111)$ surface, the initial empty spin-down component of $2 \pi^{*}$ becomes partially occupied, inducing proportional elongation of the $\mathrm{O}-\mathrm{O}$ bond length and weakening of $\mathrm{O}-\mathrm{O}$ bond strength ${ }^{44,45}$. The electron occupying the antibonding $2 \pi^{*}$ orbital of adsorbed $\mathrm{O}_{2}$ on the single-layer $\mathrm{SiC}$ is $1.55 e$ compared with $1.19 e$ on $\mathrm{Pt}(111)$ surface and $1.07 e$ in gas phase according to integrated DOS. Thus, the activation energy of $\mathrm{O}_{2}$ on the single-layer $\mathrm{SiC}$ are smaller than that on $\mathrm{Pt}(111)$ surface.

In summary, our DFT calculations suggest that novel metal-free layered $\mathrm{SiC}$ sheets with $N=1 \sim 3$ can exist stably and possess potential ORR catalytic activity due to two advantages of layered $\mathrm{SiC}$ sheets compared to $\mathrm{Pt}(111)$ surface: (i) free from CO poisoning, and (ii) lower activation energies for the RDS of ORR on layered $\mathrm{SiC}$ sheets in alkaline media than that on $\mathrm{Pt}(111)$ surface. In addition, the corresponding electronic structures are analyzed. The results show that the layered $\mathrm{SiC}$ sheets are candidates for practical applications in fuel cells.

\section{Methods}

All calculations are performed within density functional theory (DFT) framework as implemented in $\mathrm{DMol}^{3}$ code $\mathrm{e}^{46,47}$. The All Electron Relativistic core treat method is implemented for relativistic effects, which explicitly includes all electrons and introduces some relativistic effects into the core. The generalized gradient approximation (GGA) with Perdew-Burke-Ernzerhof (PBE) functional is employed to describe exchange and correlation effects ${ }^{48}$. PBE is the most common density functional in materials and surface science. However, it cannot accurate describe the van der Waals forces ${ }^{49-52}$. This is mainly because the GGA-PBE fails to describe non-local dispersion forces, which are expected to be relevant in layered inorganic compounds and weak adsorption systems. The lack of inclusion of long range correlation in the local density functional (LDF) calculations prevents the accurate calculation of the van der Waals bonds ${ }^{46}$. Therefore, a Grimme approach is adopted for dispersion corrections. Dmol ${ }^{3}$ uses a double set of numerically tabulated basis functions ${ }^{46}$. A more precise term would be "double numerical basis" to be contrasted with double zeta basis, where the radial functions are defined as Slater zeta functions. The basis set can be significantly improved by adding higher angular momentum valence polarization functions and also by core polarization functions ${ }^{46}$. Total energy for the double basis is quite uniformly higher than the ones for the extended basis sets. It has shown that the basis set produces errors in self-consistent eigenvalues and total energy of $\approx 0.00003 \mathrm{Ha}$. In this work, the double numerical atomic orbital augmented by a polarization $p$-function (DNP) is chosen as the basis set ${ }^{46}$. The accuracy of DNP is comparable to a Gaussian 6-31(d) basis ${ }^{53}$. The double basis set may be considered as a large basis especially for the larger molecules. Recent theoretical works based this basis set have shown excellent consistency with experiments ${ }^{54,55}$. We have also compared our results with that obtained based on triple numerical plus polarization (TNP), as shown in Tables S6 and S7. It can be found that the adsorption energies based on TNP are slightly larger than that based on DNP, while the activation energies and reaction energies of ORR in LH mechanism based on both basis sets are almost the same. A smearing of $0.005 \mathrm{Ha}(1 \mathrm{Ha}=27.21 \mathrm{eV})$ to the orbital occupation is applied to achieve accurate electronic convergence. The spin-unrestricted method is used for all calculations. To ensure high-quality results, the real-space global orbital cutoff radius is chosen as high as $4.6 \AA$ in the computations. The k-point density is set as $2 / 3 \times 2 / 3 \times 1$ for per unit cell. The convergence tests for k-point density are shown in Table $\mathrm{S} 8$ of supporting information, which shows that the energy of single SiC layer is converging when k-point density is larger than $2 / 3 \times 2 / 3 \times 1$. The convergence tolerance of energy is $1.0 \times 10^{-5} \mathrm{Ha}$, maximum force is $0.002 \mathrm{Ha} / \AA$, and maximum displacement is $0.005 \AA$ in the geometry optimization. The transition states for ORR elemental steps are obtained by LST/QST tools in $\mathrm{DMol}^{3}$ code. Frequency calculations are performed to confirm the location of the transition states. A conductor-like screening model (COSMO) is used to simulate a $\mathrm{H}_{2} \mathrm{O}$ solvent environment throughout the whole process. All data, except for clearly stated, are obtained under this method. The COSMO is a continuum model in which the solute molecule forms a cavity within the dielectric continuum of permittivity ${ }^{56}$. The $\mathrm{DMol}^{3} / \mathrm{COSMO}$ method has been generalized to the periodic boundary cases. The deviation of this COSMO approximation from the exact solution is small. For strong dielectrics like $\mathrm{H}_{2} \mathrm{O}$, it is less than $1 \%$. The dielectric constant is set as 78.54 for $\mathrm{H}_{2} \mathrm{O}$ solvent. Our previously theoretical work, focused on ORR on N doped CNT based on COSMO, is consistent with experiments well ${ }^{29}$. In addition, some other results also show that this implicit solvation model is an effective method to describe the solvation ${ }^{30,31}$. The solvation energies of ORR intermediates on $\mathrm{SiC}$ sheets are shown in Table S9 of supporting information and adsorption energies in a gas phase environment are shown in Table S5 of supporting information, from which we can find that $\mathrm{O}_{2}$ and $\mathrm{OH}$ are stabilized on $\mathrm{SiC}$ sheets by solvation. For layered $\mathrm{SiC}$ sheets, all simulations are performed in a 3 $\times 3$ supercell except for coverage examination of $\mathrm{O}_{2}$ adsorption, where $2 \times 2$ and $4 \times$ 4 supercells are used. The minimal distance between the $\mathrm{SiC}$ layers and their mirror images is set as $15 \AA$, which is sufficiently large to avoid the interaction between them. The Si-C bond length is $1.79 \AA$. The $\mathrm{Pt}(111)$ surface is modeled by a periodic array of Pt slabs with a vacuum width in excess of $15 \AA$. The $\mathrm{p}(3 \times 3)$ unit cells with three layer Pt slabs are used throughout in the ORR calculations. The bottom two Pt layers are fixed at their bulk positions and the top Pt layer is allowed to relax fully. Tests performed with four and five atomic layers, top two of which are allowed to relax, do not show significant differences in structural parameters. As shown in Table S10 of supporting information, the adsorption energy variation for adsorbed molecules is smaller than $0.09 \mathrm{eV}$

In this work, both LH and ER mechanisms are expected to proceed. The $\mathrm{LH}$ reaction referrs to the reaction of adsorbed hydrogen atoms with another adsorbate, and the ER reaction does the reaction of a proton from solution interacting with an adsorbate. The complete electrochemical ORR in ER mechanism involves four CPETs to $\mathrm{O}_{2}$ molecule at the cathode ${ }^{31,39}$. Electron transfers are coupled with a proton transfer as well. Barriers for electrochemical proton-transfer have been calculated for the reduction of $\mathrm{O}_{2}$ to $\mathrm{OOH}$ and $\mathrm{OH}$ to $\mathrm{H}_{2} \mathrm{O}$ on $\mathrm{Pt}^{57,58}$. In both cases, the protontransfer reaction barrier calculated is small $(0.15 \mathrm{eV}$ to $0.25 \mathrm{eV})$ at the low potential that elementary steps are exothermic, and diminishes with higher applied vol$\operatorname{tages}^{57,58}$. Similarly, as a first approximation, we expect also that barriers for electrochemical proton transfers to adsorbed species will be small and be easily surmountable at room temperature. As a result, we only calculated reaction energy for ORR in the ER mechanism. Free energies of the ORR intermediates are calculated based on a computational hydrogen electrode (CHE) model suggested by Nøskov et $\mathrm{al}^{40,59}$. Free energy change $(\Delta G)$ is determined by $\Delta G=\Delta E+\Delta Z P E-T \Delta S+$ $\Delta G_{\mathrm{pH}}+\Delta G_{\mathrm{U}}$, where $\Delta E$ is the reaction energy, $\Delta Z P E$ is the zero point energy, $T$ is temperature and $\Delta S$ is the change in the entropy. $\Delta G_{\mathrm{pH}}$ and $\Delta G_{\mathrm{U}}$ are the free energy contributions due to variations in $\mathrm{H}^{+}$concentration and electrode potential, $U$, 
respectively. In this work, we consider the contributions of $\Delta E, \Delta G_{\mathrm{pH}}$ and $\Delta G_{\mathrm{U}}$ to free energy and neglect the effects of other terms ${ }^{60}$. Effects of other terms will be included in a forthcoming publication. We assume $\mathrm{pH}=0,1,3$ and 5 for acidic medium and $\mathrm{pH}=9,11$ and 14 for alkaline medium. The $\mathrm{pH}$ effect is very hard to be considered directly in the electrolyte. Generally, it can be treated following the method directed by Nørskov et $\mathrm{al}^{40}$. At a $\mathrm{pH}$ differing from 0 , the free energy of $\mathrm{H}^{+}$ions can be corrected by the concentration: $G_{\mathrm{pH}}=-k_{\mathrm{B}} T \ln \left[\mathrm{H}^{+}\right]=\mathrm{pH} \times k_{\mathrm{B}} T \ln 10$. This $\mathrm{pH}$ dependence effect does not enter the COSMO-approach.

Naturally, ORR is a highly complicated process. Undertaking a kinetics analysis using rate constants derived from first-principles calculations would be an ideal way to determine which pathways are relevant under different conditions. Such a kinetics analysis is unfortunately difficult, since it would require rigorous double-layer effects, such as intermediate concentrations, surface coverages, or the potential drop within the interface. At here, the potential dependent rate constants $k(U)$ are obtained based on Eyring's canonical transition state theory: $k(U)=\frac{k_{\mathrm{B}} T}{h} \exp \left(\frac{-\Delta G(U)}{k_{\mathrm{B}} T}\right)$, where $k_{\mathrm{B}}$ is Boltzmann constant, $T=298.15 \mathrm{~K}, h$ is Planck constant, and $\Delta G(U)$ is the potentialdependent barrier for that process $\mathrm{s}^{3,42,43}$

1. Gasteiger, H. A., Kocha, S. S., Sompalli, B. \& Wagner, F. T. Activity benchmarks and requirements for $\mathrm{Pt}$, Pt-alloy, and non-Pt oxygen reduction catalysts for PEMFCs. Appl. Catal. B 56, 9-35 (2005).

2. $\mathrm{Yu}, \mathrm{X} . \& \mathrm{Ye}, \mathrm{S}$. Recent advances in activity and durability enhancement of $\mathrm{Pt} / \mathrm{C}$ catalytic cathode in PEMFC part II: degradation mechanism and durability enhancement of carbon supported platinum catalyst. J. Power Sources 172, 145-154 (2007).

3. Stamenkovic, V. R. et al. Trends in electrocatalysis on extended and nanoscale PtBimetallic alloy surfaces. Nat. Mater. 6, 241-247 (2007).

4. Wang, C. et al. Rational development of ternary alloy electrocatalysts. J. Phys. Chem. Lett. 3, 1668-1673 (2012).

5. Wang, C., Markovic, N. M. \& Stamenkovic, V. R. Advanced platinum alloy electrocatalysts for the oxygen reduction reaction. ACS Catal. 2, 891-898 (2012).

6. Greeley, J. et al. Alloys of platinum and early transition metals as oxygen reduction electrocatalysts. Nat. Chem. 1, 552-556 (2009).

7. Strasser, P. et al. Lattice-strain control of the activity in dealloyed core-shell fuel cell catalysts. Nat. Chem. 2, 454-460 (2010).

8. Karan, H. I. et al. Catalytic activity of platinum monolayer on Iridium and Rhenium alloy nanoparticles for the oxygen reduction reaction. ACS Catal. 2, 817-824 (2012).

9. Srivastava, R., Mani, P., Hahn, N. \& Strasser, P. Efficient oxygen reduction fuel cell electrocatalysis on voltammetrically dealloyed $\mathrm{Pt}-\mathrm{Cu}-\mathrm{Co}$ nanoparticles. Angew. Chem. Int. Ed. 46, 8988-8991 (2007).

10. Kongkanand, A., Kuwabata, S., Girishkumar, G. \& Kamat, P. Single-wall carbon nanotubes supported platinum nanoparticles with improved electrocatalytic activity for oxygen reduction reaction. Langmuir 22, 2392-2396 (2006).

11. Guo, S. \& Sun, S. FePt nanoparticles assembled on graphene as enhanced catalyst for oxygen reduction reaction. J. Am. Chem. Soc. 134, 2492-2495 (2012)

12. Zhang, Y. et al. Nanoporous graphitic- $\mathrm{C}_{3} \mathrm{~N}_{4} @$ carbon metal-free electrocatalysts for highly efficient oxygen reduction. J. Am. Chem. Soc. 133, 20116-20119 (2011),

13. Yang, S., Feng, X., Wang, X. \& Müllen, K. Graphene-based carbon nitride nanosheets as efficient metal-free electrocatalysts for oxygen reduction reactions. Angew. Chem. Int. Ed. 50, 5339-5343 (2011).

14. Yu, D., Zhang, Q. \& Dai, L. Highly efficient metal-free growth of nitrogen-doped single-walled carbon nanotubes on plasma-etched substrates for oxygen reduction. J. Am. Chem. Soc. 132, 15127-15129 (2010).

15. Liu, Z. W. et al. Phosphorus-doped graphite layers with high electrocatalytic activity for the $\mathrm{O}_{2}$ reduction in an alkaline medium. Angew. Chem. Int. Ed. $\mathbf{5 0}$ 3257-3261 (2011)

16. Choi, C. H., Park, S. H. \& Woo, S. I. Binary and ternary doping of nitrogen, boron, and phosphorus into carbon for enhancing electrochemical oxygen reduction activity. ACS Nano 6, 7084-7091 (2012).

17. Cruz-Silva, E. et al. Electronic transport and mechanical properties of phosphorus- and phosphorus-nitrogen-doped carbon nanotubes. ACS Nano 3 , 1913-1921 (2009).

18. Zhang, L. \& Xia, Z. Mechanisms of oxygen reduction reaction on nitrogen-doped graphene for fuel cells. J. Phys. Chem. C 115, 11170-11176 (2011).

19. Gong, K., Du, F., Xia, Z., Durstock, M. \& Dai, L. Nitrogen-doped carbon nanotube arrays with high electrocatalytic activity for oxygen reduction. Science $\mathbf{3 2 3}$ 760-764 (2009).

20. Yang, L. et al. Boron-doped carbon nanotubes as metal-free electrocatalysts for the oxygen reduction reaction. Angew. Chem. Int. Ed. 50, 7132-7135 (2011).

21. Yang, Z. et al. Sulfur-doped graphene as an efficient metal-free cathode catalyst for oxygen reduction. ACS Nano 6, 205-211 (2011).

22. Sun, X. J. et al. A class of high performance metal-free oxygen reduction electrocatalysts based on cheap carbon blacks. Sci. Rep. 3, 2505 (2013).

23. Zhang, Y. et al. Manageable N-doped graphene for high performance oxygen reduction reaction. Sci. Rep. 3, 2771 (2013).

24. $\mathrm{Hu}, \mathrm{X} ., \mathrm{Wu}, \mathrm{Y} ., \mathrm{Li}, \mathrm{H}$. \& Zhang, Z. Adsorption and activation of $\mathrm{O}_{2}$ on nitrogendoped carbon nanotubes. J. Phys. Chem. C 114, 9603-9607 (2010).

25. Ikeda, T. et al. Carbon alloy catalysts: active sites for oxygen reduction reaction. J. Phys. Chem. C 112, 14706-14709 (2008).
26. Lin, S. S. Light-emitting two-dimensional ultrathin silicon carbide. J. Phys. Chem. C 116, 3951-3955 (2012).

27. Eichler, A. \& Hafner, J. Molecular precursors in the dissociative adsorption of $\mathrm{O}_{2}$ on Pt(111). Phys. Rev. Lett. 79, 4481-4484 (1997).

28. Eichler, A., Mittendorfer, F. \& Hafner, J. Precursor-mediated adsorption of oxygen on the (111) surfaces of platinum-group metals. Phys. Rev. B 62, $4744-4755$ (2000).

29. Zhang, P., Lian, J. S. \& Jiang, Q. Potential dependent and structural selectivity of the oxygen reduction reaction on nitrogen-doped carbon nanotubes: a density functional theory study. Phys. Chem. Chem. Phys. 14, 11715-11723 (2012).

30. Sha, Y., Yu, T. H., Liu, Y., Merinov, B. V. \& Goddard, W. A. Theoretical study of solvent effects on the platinum-catalyzed oxygen reduction reaction. J. Phys. Chem. Lett. 1, 856-861 (2010).

31. Keith, J. A., Jerkiewicz, G. \& Jacob, T. Theoretical investigations of the oxygen reduction reaction on $\mathrm{Pt}(111)$. ChemPhysChem 11, 2779-2794 (2010).

32. Thorum, M. S., Hankett, J. M. \& Gewirth, A. A. Poisoning the oxygen reduction reaction on carbon-supported $\mathrm{Fe}$ and $\mathrm{Cu}$ electrocatalysts: evidence for metalcentered activity. J. Phys. Chem. Lett. 2, 295-298 (2011).

33. Zhang, P., Chen, X. F., Lian, J. S. \& Jiang, Q. Structural selectivity of CO oxidation on $\mathrm{Fe} / \mathrm{N} / \mathrm{C}$ catalysts. J. Phys. Chem. C 116, 17572-17579 (2012).

34. Blyholder, G. Molecular orbital view of chemisorbed carbon monoxide. J. Phys. Chem. 68, 2772-2777 (1964).

35. Mazzone, G., Rivalta, I., Russo, N. \& Sicilia, E. Interaction of CO with PdAu(111) and PdAu(100) bimetallic surfaces: a theoretical cluster model study. J. Phys. Chem. C 112, 6073-6081 (2008)

36. Liu, Z. P. \& Hu, P. General trends in CO dissociation on transition metal sufaces. J. Chem. Phys. 114, 8244-8247 (2001).

37. Michaelides, A. et al. Identification of general linear relationships between activation energies and enthalpy changes for dissociation reactions at sufaces. J. Am. Chem. Soc. 125, 3704-3705 (2003).

38. Bligaard, T. et al. The Brønsted-Evans-Polanyi relation and the volcano curve in heterogeneous catalysis. J. Catal. 224, 206-217 (2004).

39. Keith, J. A. \& Jacob, T. Theoretical studies of potential-dependent and competing mechanisms of the electrocatalytic oxygen reduction reaction on $\mathrm{Pt}(111)$. Angew. Chem. Int. Ed. 49, 9521-9525 (2010).

40. Nørskov, J. K. et al. Origin of the overpotential for oxygen reduction at a fuel-cll cathode. J. Phys. Chem. B 108, 17886-17892 (2004).

41. Lim, D. H. \& Wilcox, J. Mechanisms of the oxygen reduction reaction on defective graphene-supported Pt nanoparticles from first-principles. J. Phys. Chem. C 116, 3653-3660 (2012).

42. Eyring, H. The activated complex in chemical reactions. J. Chem. Phys. 3, 107-115 (1935).

43. Gao, W., Keith, J. A., Anton, J. \& Jacob, T. Theoretical elucidation of the competitive electro-oxidation mechanisms of formic acid on $\mathrm{Pt}(111)$. J. Am. Chem. Soc. 132, 18377-18385 (2010).

44. Wang, C. M., Fan, K. N. \& Liu, Z. P. Origin of oxide sensitivity in gold-based catalysts: a first principle study of $\mathrm{CO}$ oxidation over Au supported on monoclinic and tetragonal $\mathrm{ZrO}_{2}$. J. Am. Chem. Soc. 129, 2642-2647 (2007).

45. Ou, L., Yang, F., Liu, Y. \& Chen, S. First-principle study of the adsorption and dissociation of $\mathrm{O}_{2}$ on $\mathrm{Pt}(111)$ in acidic media. J. Phys. Chem. C 113, 20657-20665 (2009).

46. Delley, B. An all-electron numerical method for solving the local density functional for polyatomic molecules. J. Chem. Phys. 92, 508-517 (1990).

47. Delley, B. From molecules to solids with the $\mathrm{DMol}^{3}$ approach. J. Chem. Phys. 113, 7756-7764 (2000).

48. Perdew, J. P., Burke, K. \& Ernzerhof, M. Generalized gradient approximation made simple. Phys. Rev. Lett. 77, 3865-3868 (1996).

49. Graziano, G., Klimeš, J., Fernandez-Alonso, F. \& Michaelides, A. Improved description of soft layered materials with van der Waals density functional theory. J. Phys.: Condens. Matter 24, 424216 (2012).

50. Carrasco, J., Klimeš, J. \& Michaelides, A. The role of van der Waals forces in water adsorption on metals. J. Chem. Phys. 138, 024708 (2013).

51. Björkman, T., Gulans, A., Krasheninnikov, A. V. \& Nieminen, R. M. van der Waals bonding in layered compounds from advanced density-functionals firstprinciples calculations. Phys. Rev. Lett. 108, 235502 (2012).

52. Schimaka, L. et al. Accurate surface and adsorption energies from many-body perturbation theory. Nat. Mater. 9, 741-744 (2010).

53. Liu, P. \& Rodriguez, J. A. Catalysts for hydrogen evolution from the $[\mathrm{NiFe}]$ hydrogenase to the $\mathrm{Ni}_{2} \mathrm{P}(001)$ surface: the importance of ensemble effect. J. Am. Chem. Soc. 127, 14871-14878 (2005).

54. Rodriguez, J. A. et al. Activity of $\mathrm{CeO}_{\mathrm{x}}$ and $\mathrm{TiO}_{\mathrm{x}}$ nanoparticles grown on $\mathrm{Au}(111)$ in the water-gas shift reaction. Science 318, 1757-1760 (2007).

55. Wu, Z. et al. Structure sensitivity of low-temperature NO decomposition on $\mathrm{Au}$ surfaces. J. Catal. 304, 112-122 (2013).

56. Klamt, A. \& Schüürmann, G. COSMO: A new approach to dielectric screening in solvents with explicit expressions for the screening energy and its gradient. J. Chem. Soc. 2, 799-805 (1993).

57. Janik, M. J., Taylor, C. D. \& Neurock, M. First-principles analysis of the initial electroreduction steps of oxygen over $\mathrm{Pt}(111)$. J. Electrochem. Soc. 156, B126-B135 (2009). 
58. Tripkovic, V., Skúlason, E., Siahrostami, S., Nørskov, J. K. \& Rossmeisl, J. The oxygen reduction reaction mechanism on $\mathrm{Pt}(111)$ from density functional theory calculations. Electrochim. Acta 55, 7975-7981 (2010).

59. Yu, L., Pan, X., Cao, X., Hu, P. \& Bao, X. Oxygen reduction reaction mechanism on nitrogen-doped graphene: a density functional theory study. J. Catal. 282, 183-190 (2011).

60. Roudgar, A., Eikerling, M. \& van Santen, R. Ab initio study of oxygen reduction mechanism at $\mathrm{Pt}_{4}$ cluster. Phys. Chem. Chem. Phys. 12, 614-620 (2010).

\section{Acknowledgments}

This work was financially supported by National Key Basic Research and Development Program (Grant No. 2010CB631001), Natural Science Foundation of Jiangsu (No. SBK201341900), China Postdoctoral Science Foundation (No. 2013M541611), and the Senior Intellectuals Fund of Jiangsu University (No. 12JDG094 and 13JDG032). We acknowledge the supports from High Performance Computing Center (HPCC) of Jilin University.

\section{Author contributions}

P.Z. conceived the initial idea of this research, performed the computer simulations and wrote the paper. B.B.X., X.L.H., Y.F.Z. and Q.J. participated in the discussion and revised the manuscript. Y.F.Z. and Q.J. guided the work.

\section{Additional information}

Supplementary information accompanies this paper at http://www.nature.com/ scientificreports

Competing financial interests: The authors declare no competing financial interests.

How to cite this article: Zhang, P., Xiao, B.B., Hou, X.L., Zhu, Y.F. \& Jiang, Q. Layered SiC Sheets: A Potential Catalyst for Oxygen Reduction Reaction. Sci. Rep. 4, 3821; DOI:10.1038/ srep03821 (2014).

This work is licensed under a Creative Commons Attribution 3.0 Unported license. To view a copy of this license, visit http://creativecommons.org/licenses/by/3.0 